\title{
Design and deployment of an integrated instrumentation system in a monitoring well at the Aquistore Geological $\mathrm{CO}_{2}$ storage project, Saskatchewan, Canada
}

\author{
G Zambrano-Narvaez University of Alberta, Canada \\ R Chalaturnyk University of Alberta, Canada \\ K Worth Petroleum Technology Research Centre, Canada
}

\begin{abstract}
This paper provides an overview of the Aquistore geological $\mathrm{CO}_{2}$ storage project initiated in Western Canada in early June 2011. The Aquistore site is located in south-eastern Saskatchewan, Canada, near the city of Estevan. Initially, 1,000 tonnes/day of $\mathrm{CO}_{2}$ will be injected into a deep, highly saline aquifer at near $3.4 \mathrm{~km}$ depth in the Williston Basin. The injection interval is characterised by a thick sandstone aquifer of the Deadweed and Winnipeg Formations, and is overlain by the Icebox Member of the Winnipeg Formation and by the Praire Evaporite. The measurement, monitoring and verification program of Aquistore provides an opportunity to develop and implement effective methods for monitoring $\mathrm{CO}_{2}$ storage sites and ensure conformance of the storage process through continuous monitoring. In particular this paper will focus on the completion of the dedicated observation well, located at $150 \mathrm{~m}$ from the main injector, containing a fibre-optic distributed temperature system, fibre-optic distributed acoustic system, multiple pressure and temperature gauges and one fluid recovery system. Many of these tools are able to measure over the full depth of the well $(3,400 \mathrm{~m})$. This integrated down-hole monitoring system was casing-conveyed, accomplished by wrapping the tools around the main casing during its installation. The integration of the information from this monitoring program will provide valuable insights for similar projects and the professional community considering the deployment of unique multiple-instrument strings in the field of geological storage of $\mathrm{CO}_{2}$.
\end{abstract}

\section{Introduction}

Coal is the world's most abundant fossil fuel and has always played a significant and ever growing role in the generation of electricity. While coal-fired power generation will remain an important component of Canada's energy industry, environmental concerns could limit its wider development. Coal-fired processes result in more greenhouse gas emissions than gas-fired generation (US EIA 2014). Canada's federal government is particularly focused on reducing carbon emissions from coal-fired power plants by supporting the development of safe, cost-effective technologies to prevent the waste carbon from accumulating in the atmosphere (EC 2014).

The capture and geological storage of $\mathrm{CO}_{2}$, a vital component in the energy innovation value chain, has been identified as a critical enabling technology that would reduce $\mathrm{CO}_{2}$ emissions significantly while also allowing coal and other fossil fuels to meet the world's pressing energy needs and, perhaps most importantly, maintain a social license to forge ahead with their rapid pace of development. In 2010, the Saskatchewan's provincially owned energy utility - SaskPower - announced plans to commission the world's largest commercial-scale carbon capture, utilisation and storage (CCUS) project associated with coal-fired power plant (Global CCS Institute 2013). 


\subsection{Background}

Aquistore, an independent research and monitoring project intends to demonstrate that storing liquid carbon dioxide $\left(\mathrm{CO}_{2}\right)$ deep underground (in a brine and sandstone formation) is a safe, workable solution to reduce greenhouse gases (GHGs). While SaskPower owns the Aquistore assets and long term liability, the Petroleum Technology Research Centre will manage the Aquistore project (Worth et al. 2014). The geologic $\mathrm{CO}_{2}$ storage site is located near the city of Estevan in south-eastern Saskatchewan (Figure 1). The $\mathrm{CO}_{2}$ will be injected into a deep, highly saline clastic formation at a depth of around $3.4 \mathrm{~km}$ in the Deadwood and Winnipeg (Black Island Member) formations that are the deepest sedimentary units in the Williston Basin.

The Winnipeg formation is divided into two regionally extensive subunits: the Icebox and the Black Island members. The Icebox Member - the primary sealing unit - is comprised of shale of approximately 30 metres thick. The Black Island Member is constituted of sandstones approximately 40 metres thick. The Deadwood formation of roughly 250 metres thick is comprised of four members $A$ through $D$, and the three main lithologies are a basal conglomerate, interbedded sandstone and shale, and thin beds of limestone (Greggs 2000). The reservoir temperature is $119^{\circ} \mathrm{C}$, and average reservoir pressure is $35 \mathrm{MPa}$. Preliminary laboratory measurements on core plugs gave average porosity and permeability values of $6 \%$ and $5 \mathrm{~m} / \mathrm{D}$ respectively (Peck et al. 2014). Additional geomechanical tests under in situ conditions on core recovered from the injection and observation wells are underway.

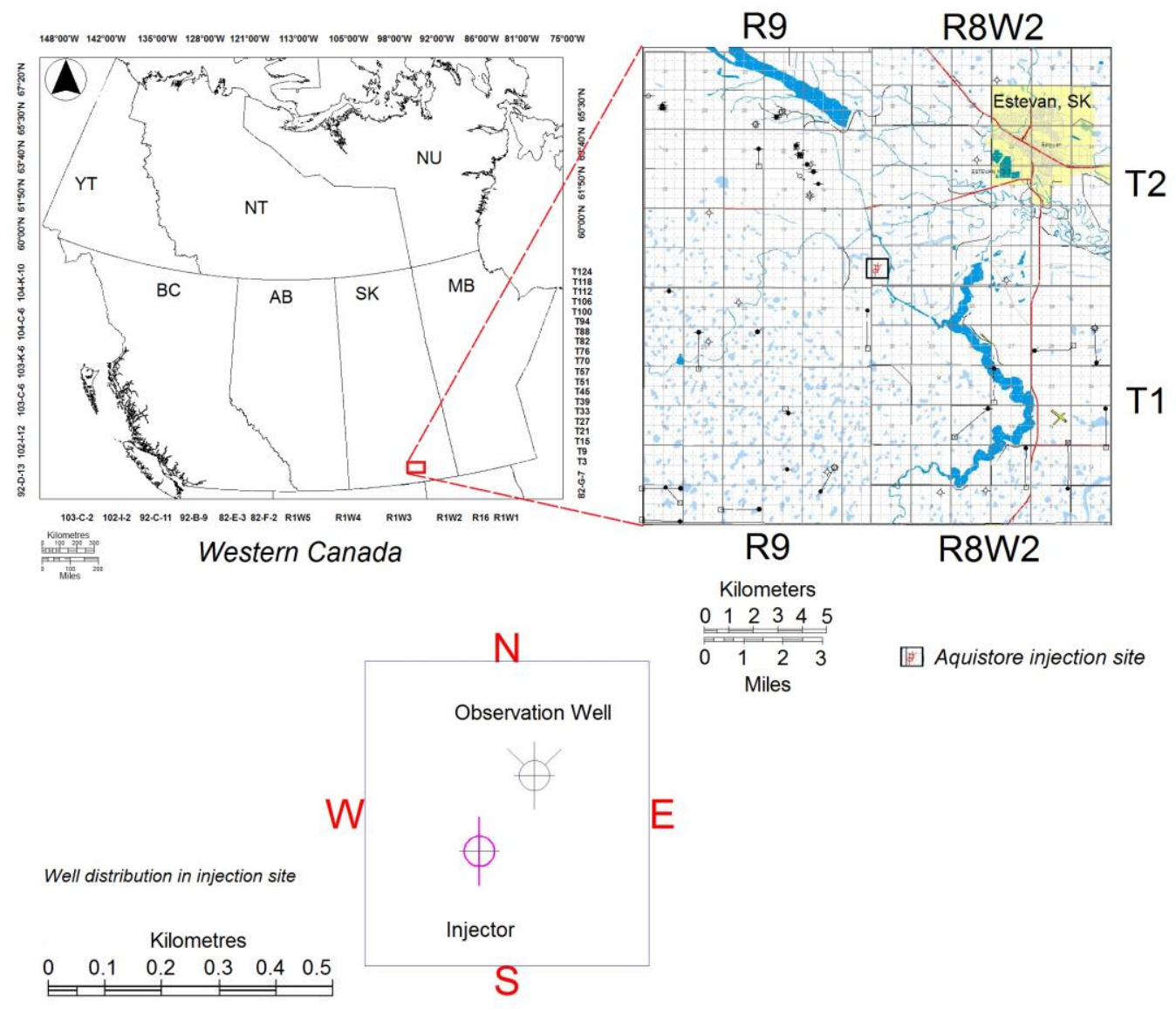

\section{Figure 1 Location and well distribution of Aquistore site, Saskatchewan, Canada}

Aquistore has recently completed two state-of-the-art 'smart' wells: a $\mathrm{CO}_{2}$ injection well and an observation well located $150 \mathrm{~m}$ apart and to a depth of $3,400 \mathrm{~m}$. These are the deepest wells in Saskatchewan, representing AUD $15 \mathrm{M}$ of development and installation costs. When $\mathrm{CO}_{2}$ injection begins, currently scheduled for 2015, these two wells will provide real-time measurement, monitoring and verification (MMV) data that will serve as the foundation for validating predictive modelling. Aquistore's 
comprehensive MMV program also includes a permanent seismic array that will be used to predict the fate of the $\mathrm{CO}_{2}$ plume.

Surveillance technologies deployed on the Aquistore $\mathrm{CO}_{2}$ injection and observation wells, which include downhole pressure sensors, fluid recovery system (FRS) and fibre optic based distributed temperature (DTS) and acoustic (DAS) sensors, will provide unprecedented monitoring data on the dynamics of phase changes (i.e. supercritical to liquid to gas phase shifts) from the wellhead to the geological formation associated with $\mathrm{CO}_{2}$ injection (Rostron et al. 2014). Real time monitoring data of these phase changes in the injection stream under fully integrated operational conditions provides unparalleled information for understanding geological storage under these conditions and optimising completion systems. The potential also exists for the DAS system to capture energy releases that may result from rapid phase change behaviour of the injection stream during unexpected events in the CCUS operations providing invaluable data on how completion systems perform under these conditions.

Passive seismic monitoring will be conducted continuously using a subset of the permanent surface seismic array, downhole geophone array, earthquake grade seismometers and DAS. The purpose of passive monitoring is to document microseismicity and associated stress changes in the reservoir and overlying zone that are associated with the injection process, and to include these stress changes in geomechanical modelling. Data collection began in July 2012 with 50 continuously monitored stations. $\mathrm{As}^{\mathrm{CO}_{2}}$ injection commences coverage up to 650 surface stations can be customised to track the plume.

Regular sampling and chemical analysis of reservoir fluids before, during, and after $\mathrm{CO}_{2}$ injection is an effective means of documenting the compositional evolution imposed by $\mathrm{CO}_{2}$ emplacement (Czernichowski-Lauriol et al. 1996; Gunter et al. 2000). When combined with mineralogical studies, reservoir modelling work, and geophysical monitoring results, the reservoir fluid sampling program effectively documents the dynamic mass partitioning of $\mathrm{CO}_{2}$ among distinct physical and chemical trapping mechanisms. Successful application of this integrative approach requires monitoring a broad range of chemical and isotopic parameters within sampled reservoir fluids (Emberley et al. 2005). Aquistore's smart observation well comprises a downhole FRS (patent pending) that permits the acquisition of reservoir fluids at reservoir pressure. By acquiring fluid samples under pressure at the surface and analysing their composition, a comparison can then be made with fluid samples taken under ambient conditions and possibly aid in assessing depressurisation effects on the composition of recovery fluids.

This paper provides an overview of the design, deployment and early history of the observation well of Aquistore.

\section{Observation well}

Figure 2 illustrates the completion geometry of the observation well in relation to the geological formations. The well is located $150 \mathrm{~m}$ away from the newly drilled injection well, and was instrumented with downhole pressure and temperature sensors, DTS/DAS lines and a FRS sample port. The pressure gauges and FRS were packaged in steel housings pre-welded to multiple outside sections of casing $(114.3 \mathrm{~mm}$ in diameter) and designed for mechanical protection during the installation. Additional computational fluid dynamics (CFD) was conducted to optimise the geometry of these outside-casing-conveyed housing with the objective to preserve the streamlines of the flow during cementing and reduce the possibility of a micro-annulus (Zambrano-Narvaez et al. 2013). The instrumentation string was installed in a borehole of $219 \mathrm{~mm}$ diameter.

Dual sapphire pressure/temperature sensors were installed at depth of 3,305 $\mathrm{m}$, and single sensors at depths of 3,235, 3,177 and 3,137 m, for a total of five sensors. The FRS sampling port was installed at depth of $3,232 \mathrm{~m}$. The DTS/DAS lines were installed from the surface to $2,850 \mathrm{~m}$ depth. 


\subsection{Cementing job}

The cementing job was designed for a two pump stages. The first stage was completed successfully (Figure 3(b)). However, while starting the second stage, the 'bomb' used to open the stage collar hit an obstruction at 1,650 metres below the kelly bush (mKB), and did not reach the stage tool. Therefore, the completion of this well was divided into two cement squeezes: through the stage tool (Figure 3(c)) and down the annulus (Figure 3(d)).

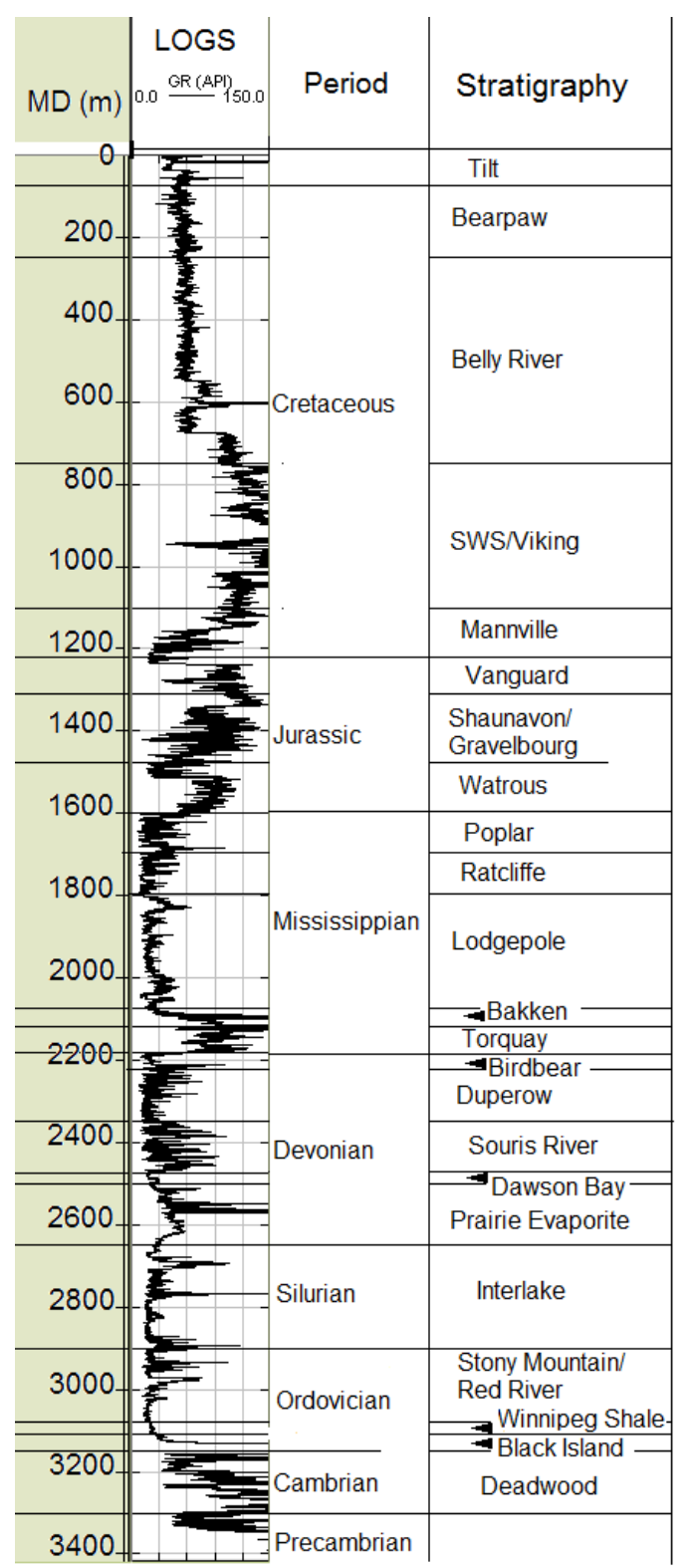

Regular cement

CO - Resistant cement 1. Pressure and temperature sensors

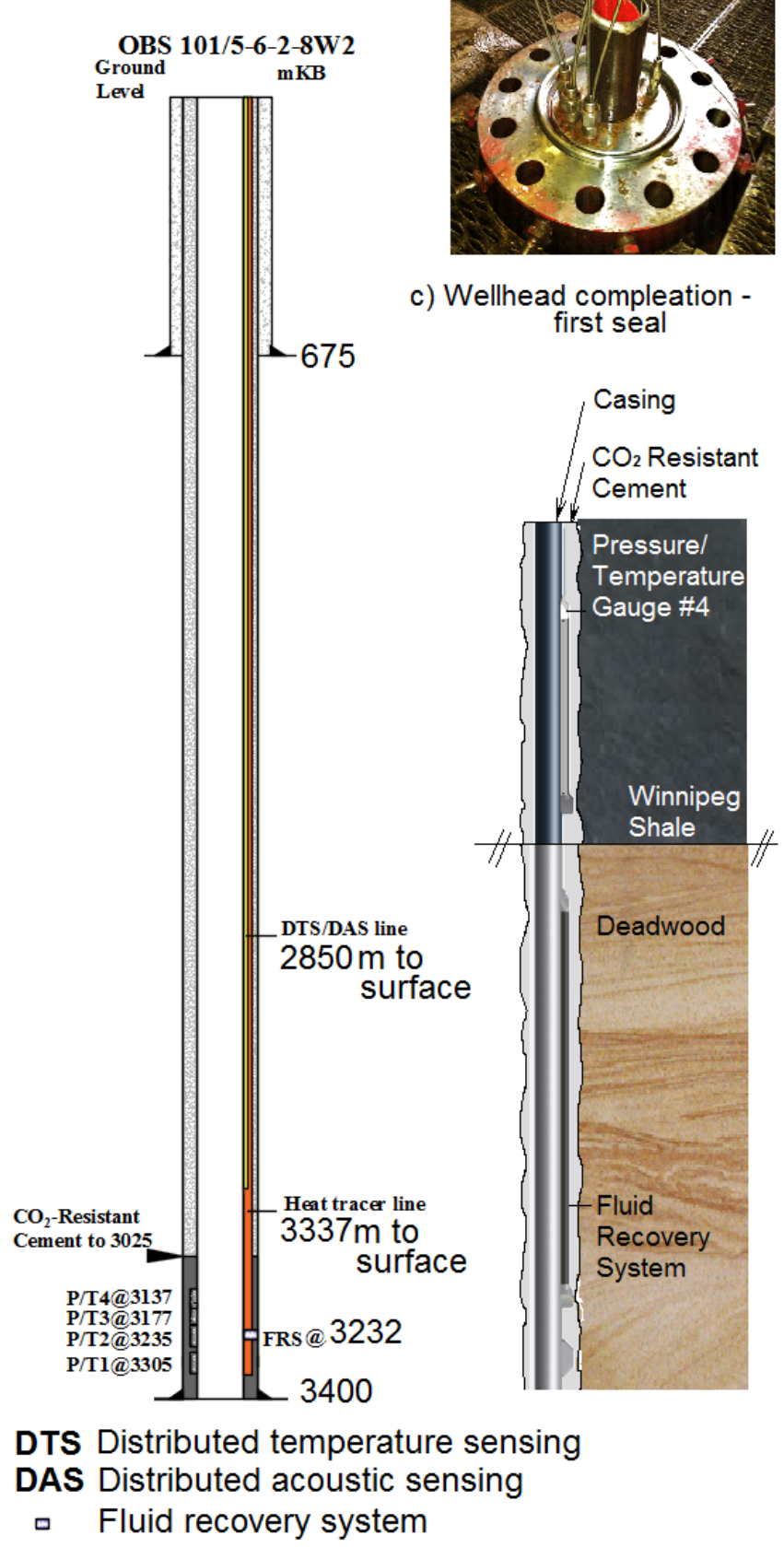

a) Wellbore log and completion configuration

b) Configuration details

\section{Figure 2 Schematic of instrumentation well configuration and geology}

All fluids during the first stage cementing operation were pumped down the casing and up the annulus between the casing and borehole walls. Prior to running the instrumentation string into the borehole, the 
mud was circulated and conditioned for cementing (Figure 3(a)). The invert drilling fluid - oil-based mud had an average density value of $1.33 \mathrm{~g} / \mathrm{cm}^{3}$. Once the instrumentation string had been deployed at their final depth and confirmed to all be operational, a spacer fluid $\left(8 \mathrm{~m}^{3}\right.$ mud with a density equal to $\left.1.3 \mathrm{~g} / \mathrm{cm}^{3}\right)$ was pumped at an average flow rate of $0.74 \mathrm{~m}^{3} / \mathrm{min}$. The spacer was followed by $30.89 \mathrm{~m}^{3}$ of lead cement slurry (FlexSeal - with a density equal to $1.6 \mathrm{~g} / \mathrm{cm}^{3}$ ), which was pumped at an average flow rate of $0.62 \mathrm{~m}^{3} / \mathrm{min}$. Immediately behind the lead cement, $9.64 \mathrm{~m}^{3}$ of Special $\mathrm{CO}_{2}$ resistant cement slurry (density equal to $1.9 \mathrm{~g} / \mathrm{cm}^{3}$ ) was pumped at an average flow rate of $0.75 \mathrm{~m}^{3} / \mathrm{min}$. Once the prescribed volume of cement was pumped into the casing, it was followed immediately with $9.9 \mathrm{~m}^{3}$ of water, $2.0 \mathrm{~m}^{3}$ of mud spacer and $13.5 \mathrm{~m}^{3}$ of invert fluid, which were used as displacing fluid to complete the circulation of the first stage at an average flow rate of $0.78 \mathrm{~m}^{3} / \mathrm{min}$ (Figure $3(b)$ ).

Two different cement types were used in the squeeze cementing operation through the stage tool: first, $32.0 \mathrm{~m}^{3}$ of lead conventional cement $(1: 1: 2$ Class $\mathrm{G})$ with density equal to $1.7 \mathrm{~g} / \mathrm{cm}^{3}$, followed by $5.0 \mathrm{~m}^{3}$ of tail cement $(0: 1: 0$ Class $\mathrm{G})$ that includes water loss additives with density equal to $1.9 \mathrm{~g} / \mathrm{cm}^{3}$ (Figure $3(\mathrm{c})$ ). This was immediately followed by the squeezing cement injected through the annulus with $30.5 \mathrm{~m}^{3}$ of conventional cement (1:1:2 class $G$ ) to complete the cementing job of the observation well (Figure $3(d)$ ).

\section{OBS 101/5-6-2-8W2}

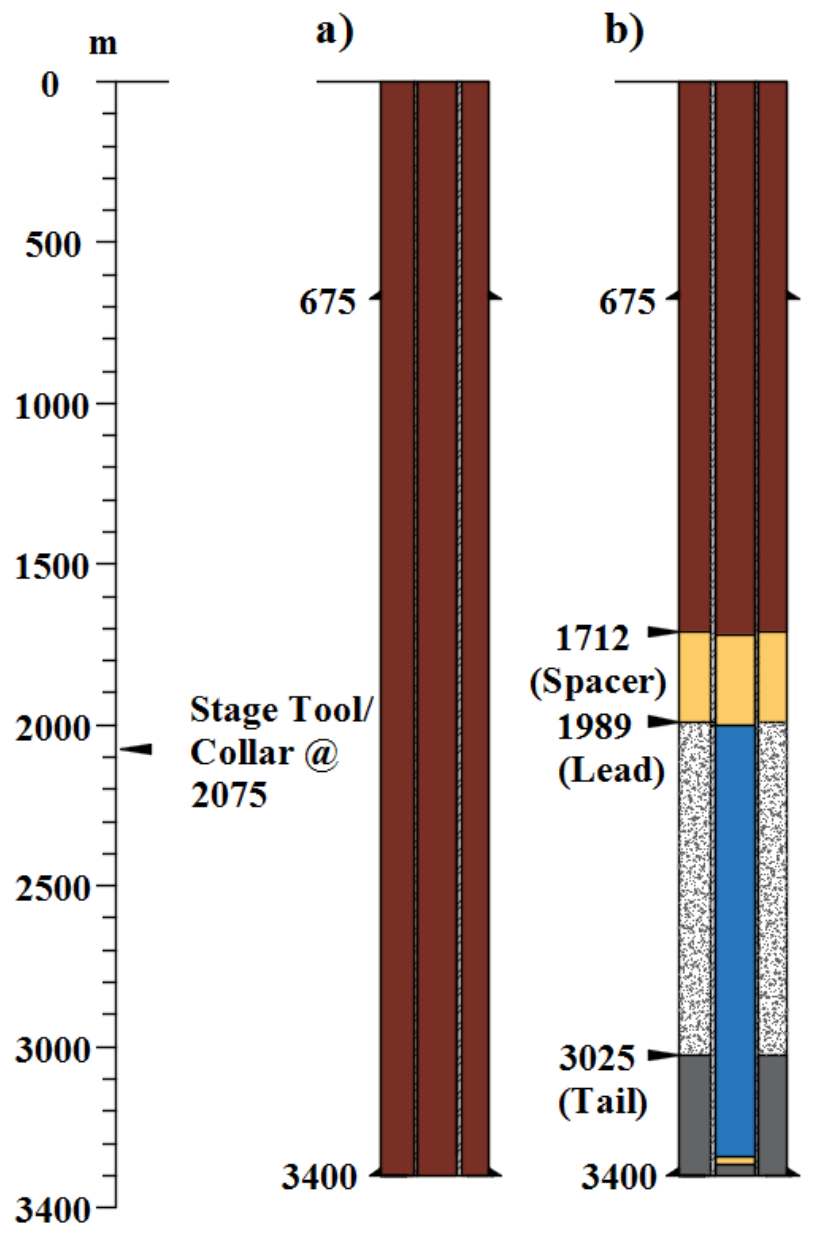

c)

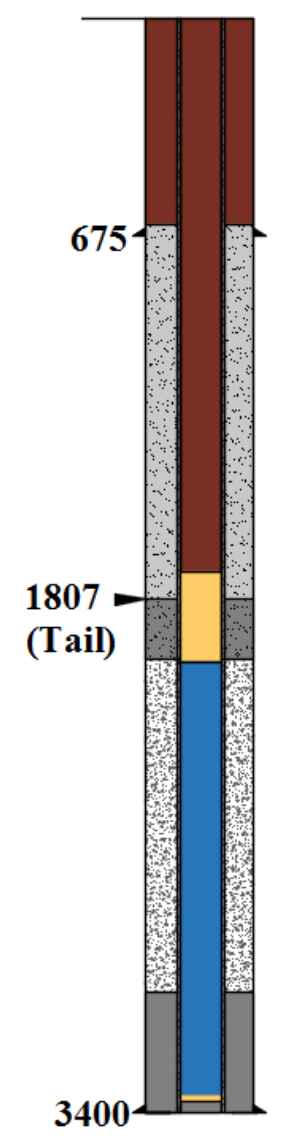

d)

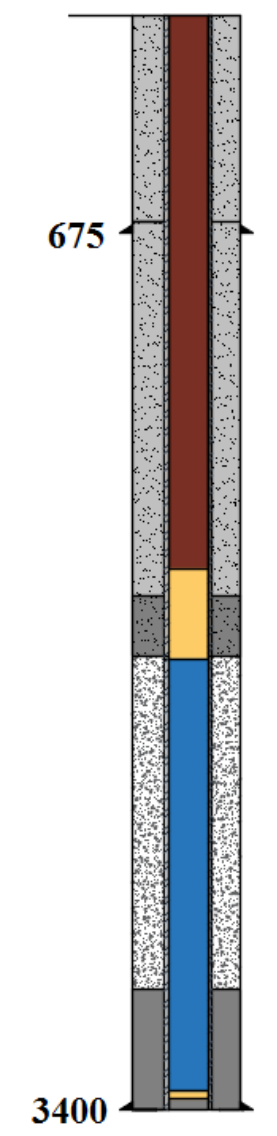

Drilling mud/Invert

Mud/Spacer

Lead Cement/FlexSeal

Water

Tail $\mathrm{CO}_{2}$ - Resistant Cement

Lead Cement - class "G" 1:1:2

Tail Cement - class "G" 0:1:0

Figure 3 Steps in the cementation of the observation well: (a) circulation and condition mud for cementing; (b) first cement pump stage - estimated depth of cement 


\section{top is $1,989 \mathrm{~m}$; (c) squeeze cement through the stage tool - estimated depth} of cement top is $640 \mathrm{~m}$; (d) squeeze cement through the annulus

\subsubsection{Pressure and temperature observations during cementing operations}

Figure 4 provides 48 hours of the downhole pressure and temperature recorded observations during the installation of the instrumentation string and the cementing operation.

The initial pressure and temperature readings of Figure 4 started when the casing shoe was at depth of $1,480 \mathrm{~m}$. The readings indicate that while the instrumentation string was running into the wellbore the pressure and temperature increased with a constant rate. Using the invert density the estimated rate of instrumentation string entering the borehole was $80 \mathrm{~m} / \mathrm{h}$. The casing shoe reached the bottom of the hole $(3,400 \mathrm{~m})$ at $1351 \mathrm{~h}$ on 6 November, and the recorded pressure at 3,302 $\mathrm{m}$ depth was $44.38 \mathrm{MPa}$, which is 9.56 MPa higher than the reservoir pressure of $34.81 \mathrm{MPa}$, measured at depth of the middle perforation $(3,260 \mathrm{~m})$ at the injection well, but lower than the fracture gradient of $14.93 \mathrm{kPa} / \mathrm{m}$. Note the concomitant decrease in downhole temperature as the colder invert fluid began to circulate past the downhole gauges.

The circulation and conditioning of the mud for the first stage cement job started at $0200 \mathrm{~h}$ on 7 November. Once the pre-cement mud became the dominant fluid in the wellbore, the pressure began to decrease slightly to reflect the change in its density $\left(1.28 \mathrm{~g} / \mathrm{cm}^{3}\right)$ compared to the inverter fluid density. Note that at $0330 \mathrm{~h}$ the shallower pressure and temperature sensor was disconnected unintentionally for the remaining cementing program. The conditioning of the mud ended at $0600 \mathrm{~h}$, followed by the pre-cementing safety protocols. The first stage cementing program started and ended at approximately $0745 \mathrm{~h}$ and $1010 \mathrm{~h}$, respectively. The bomb to unlock the stage collar for the second stage was dropped at $1015 \mathrm{~h}$ but it did not reach the stage tool and hit an obstruction at $1,650 \mathrm{mKB}$. This was followed by several pumping tests to pressurise the casing to unlock/open the stage collar, which concluded without success at $1300 \mathrm{~h}$. The remainder of the pressure and temperature readings are associated with first stage cement hydration and equalisation to the reservoir conditions. 


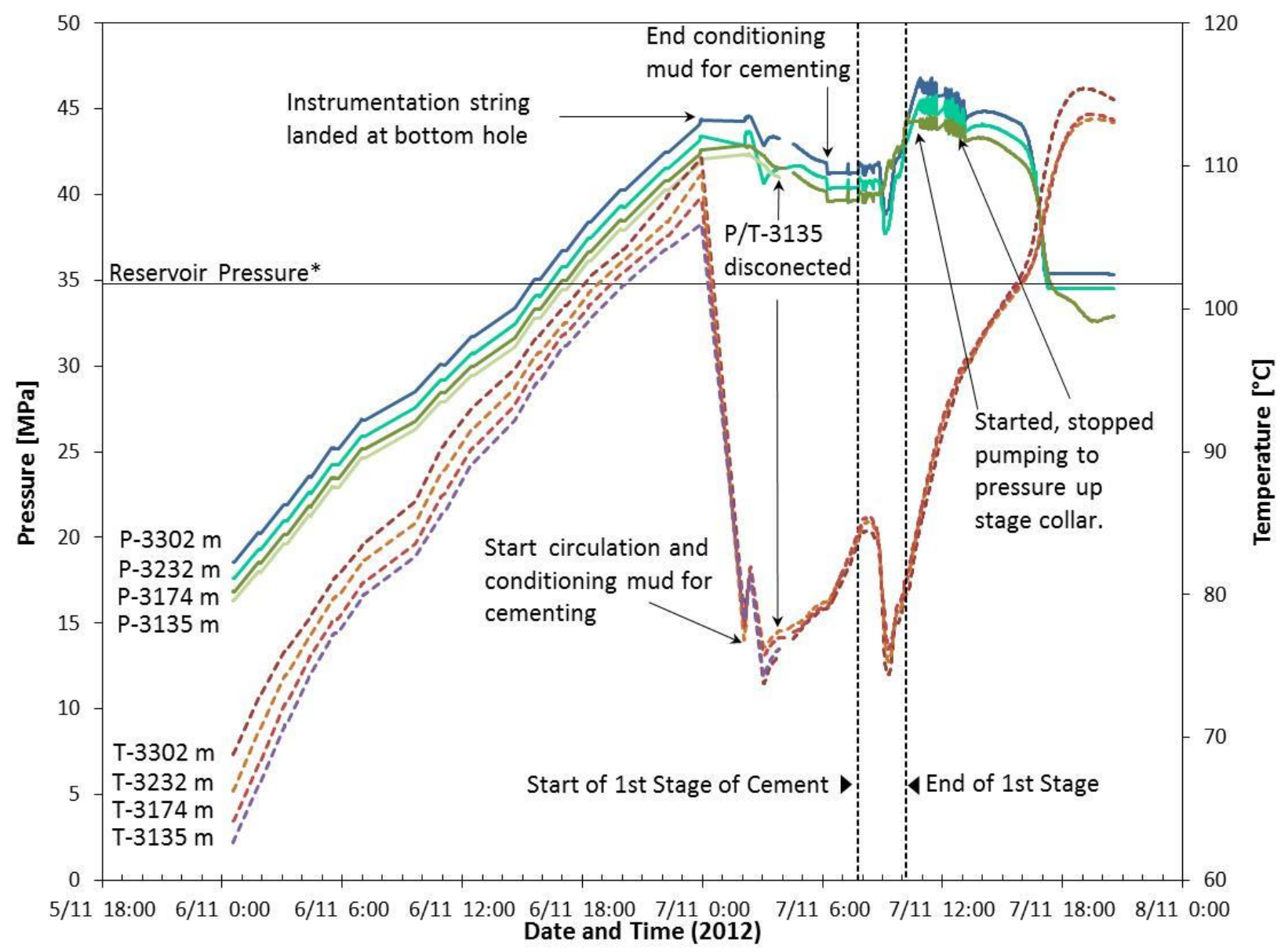

Figure 4 Pressure and temperature records during the installation and first stage
cement of the observation well completion

It is informative to normalise the downhole pressures to the density or unit weight of water since the cementing operation involved fluid of various densities. This approach provides additional insight into the dynamics that are occurring downhole.

Figure 5 shows normalised pressures obtained from equivalent densities that occur during the cementing process, and normalised temperatures (normalised to the initial temperature at each sensor depth). The normalised results indicate that the downhole pressure did not change significantly when the circulation of the spacer mud began at $0745 \mathrm{~h}$ due to similar equivalent densities between the spacer mud (1.3) and pre-cement mud (1.28) in borehole. Once the spacer mud circulation concluded, it was followed by a short shutting period of $8 \mathrm{~min}$. 


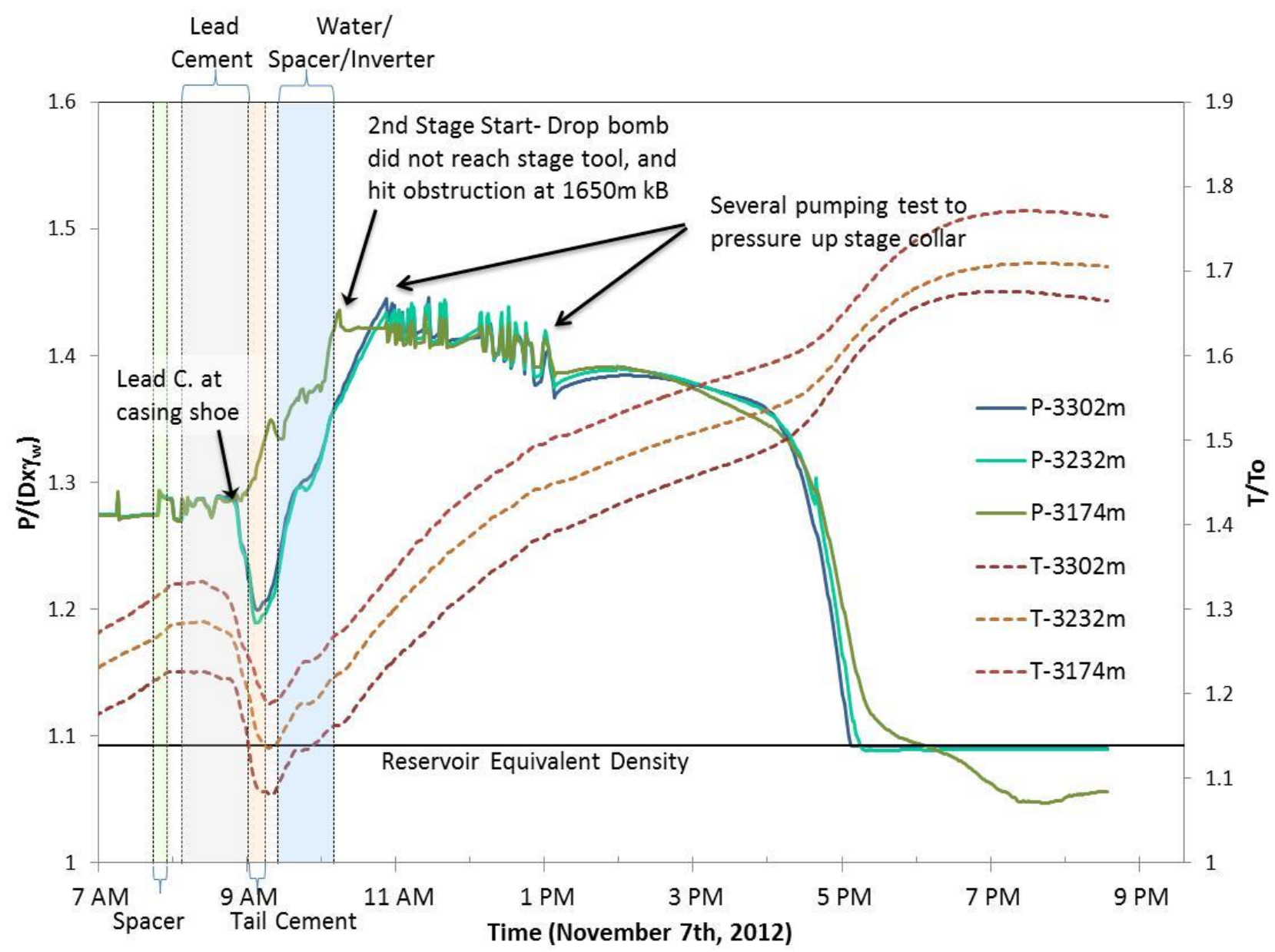

\section{Figure 5 Equivalent density and normalised temperature during the first stage cement program}

The lead cement circulation began at $0803 \mathrm{~h}$, and the cement front reached the casing shoe at $0853 \mathrm{~h}$. Note that from this point the deeper gauges located at the Deadwood Formation sensed a decrease in annular pressure, while the shallower sensor located at the Black Island Formation sensed an increase in annular pressure. The latter pressure signal was expected for all the sensors given that the circulated cement (heaver fluid) was displacing the invert fluid (lighter fluid). Once the lead cement circulation concluded, it was followed by the special, $\mathrm{CO}_{2}$ resistant, tail cement circulation that began at $0902 \mathrm{~h}$. Note that the deeper pressure gauges sensed a pressure/density increase at $0907 \mathrm{~h}$ and this trend was maintained through the remainder of the first cement stage program.

After the prescribed volume of tail cement was pumped into the casing, it was followed by a short shutting period and water, spacer mud and inverter fluid that were used as a displacing fluids to complete the circulation of the specified cement volume for the first stage.

One explanation for the different pressure/density signals of the deeper and shallow pressure gauges soon after the lead cement front passed the casing shoe is the phenomenon of free fall during primary cementing (Beirute 1984). The densities of the cement slurries (lead and tail) are greater than the density of the mud initially in the well. Because of this density difference, the lower density mud can experience a vacuum when the heavier fluids are being pumped down the casing. Additional analysis is planned to history match this field data and to assess the wellbore integrity under 'in situ' conditions.

\subsection{Fluid recovery system}

Recovery of downhole fluid samples at in situ conditions is required for analysis of geochemical, isotopic composition and/or dissolved gases. However, permanent installations of deep (>1,000 $\mathrm{m}$ depth) downhole 
fluid ports are rarely included in observation-well designs because it presents a number of technical difficulties during the completion and/or recovery stages.

The FRS (patent pending) was developed at the University of Alberta and comprises a downhole device specially designed to allow reservoir fluids to be sampled and brought to the surface under 'in situ' conditions within permanent or fully cemented observation wells (Figure 6).

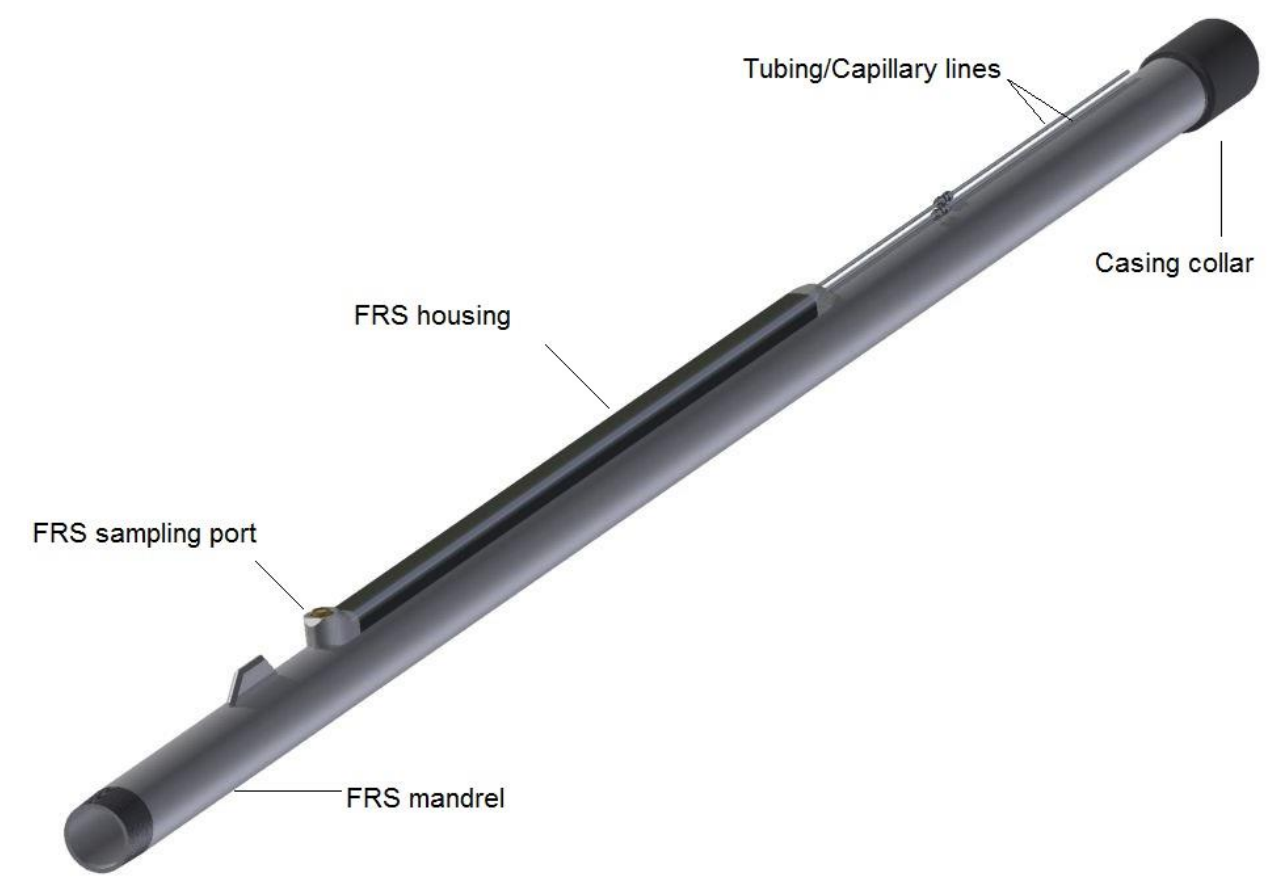

\section{Figure 6 Installation schematic of FRS mandrel}

The FRS housing installed at Aquistore is very similar in size and shape to the pressure sensor carrier. The FRS port is pushed into the borehole walls after reaching the sampling interval in order to enhance hydraulic communication with the reservoir. The housing design of the FRS is the result of mechanical and computational flow analysis undertaken to reduce flow impedance to as low as possible, preserving the streamlines of the flow during cementing (Figure 7). FRS uses a configuration that incorporates a system of shuttle valves located at the sampling interval. Each sampling port is connected to the surface by two stainless steel tubing/capillary lines $(6.35 \mathrm{~mm}$ in diameter) that are connected to a fluid recovery control panel. The fluids are sampled and stored in the FRS housing and collected under pressure through the capillary lines. In the case of Aquistore, fluid from 3,200 metres below the surface can be sampled, preserved and brought to surface.

The Aquistore site has an insulated shed $3.7 \mathrm{~m}$ wide by $2.5 \mathrm{~m}$ long mounted on skids located adjacent to the observation well that is dedicated to the FRS surface control panel.

The FRS was commissioned at the Aquistore site on 2013. Since 2014, multiple base line samples have been recovered for analysis. 


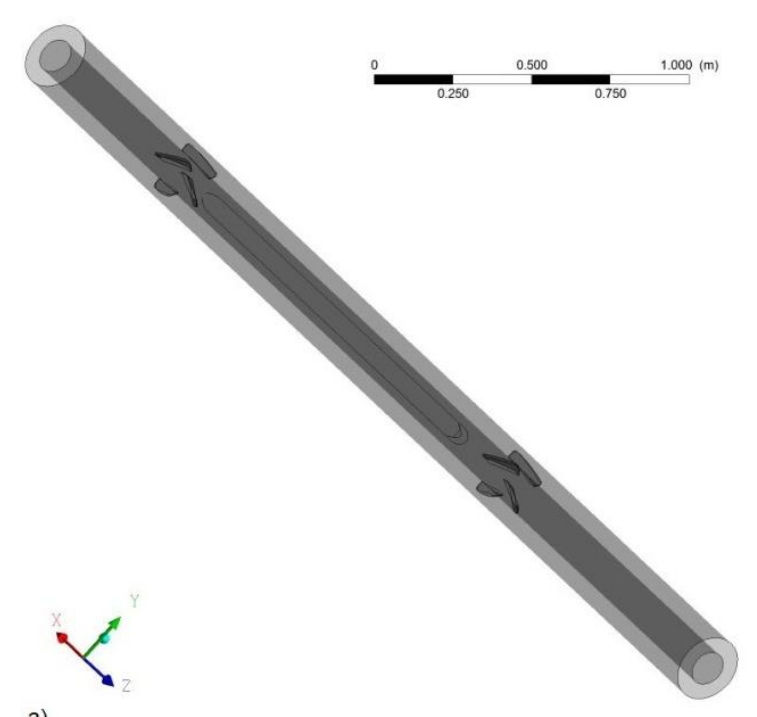

a)

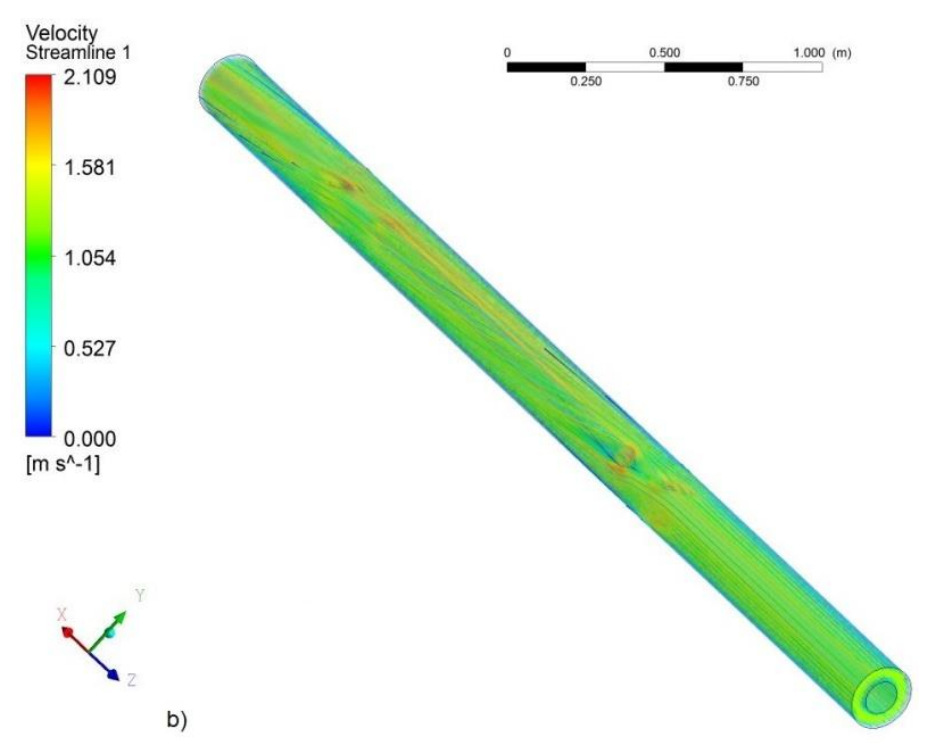

Figure 7 Preliminary computational fluid dynamics of cement circulation through FRSmandrel/borehole-walls annular area: (a) model geometry; (b) annular velocity streamlines

\section{Conclusion}

The observation well at the Aquistore project has allowed direct monitoring and measurements at reservoir level of multiple variables through geophysical, geochemical and geomechanical instrumentation, as well as the opportunity to carry out wellbore integrity studies under 'in situ' conditions.

Downhole pressure gauges capture the dynamics of cement displacement; a key element during the execution of the job, post-job review, and assessment of future well integrity. A detailed analysis of well completion, cementing behaviour, and annular flow behaviour is critical for the integrity assessment of this type of well. Synthesis of this information provides the basis for recommendations regarding the deployment of downhole technologies in observation wells used for monitoring and verification of $\mathrm{CO}_{2}$ movement. The application of the innovative FRS, permanently cemented at the reservoir level, is showing promise as an effective technology for geochemical monitoring.

\section{Acknowledgement}

The authors thank the sponsors of the Aquistore Project for permission to publish this paper and for the funding to implement these monitoring technologies. Incremental financial support for this program was provided through the Helmholtz Alberta Initiative and the Foundation CMG Industrial Research Consortia on Reservoir Geomechanics for Unconventional Resources. The monitoring technologies discussed in this paper comprise only a component of the MMV technologies deployed within the Aquistore Project. The complete MMV program has been the ongoing responsibility of the Aquistore Scientific and Engineering Research Committee comprised of Don White (chair), Chris Hawkes, Ben Rostron, Jim Johnson, Jim Sorenson, Rick Chalaturnyk and Kyle Worth.

\section{References}

Beirute, RM 1984, 'The phenomenon of free fall during primary cementing', Proceedings of the 59th Annual Technical Conference and Exhibition, Society of Petroleum Engineers, Richardson, TX, $12 \mathrm{p}$.

Czernichowski-Lauriol, I, Sanjuan, B, Rochelle, C, Bateman, K, Pearce, J \& Blackwell, P 1996, 'Deep injection disposal of hazardous and industrial waste: analysis of the geochemical aspects of the underground disposal of $\mathrm{CO}_{2}$ ', in JA Apps \& CF Tsang (eds), Deep injection disposal of hazardous and industrial waste: scientific and engineering aspects, Academic Press, San Diego, pp. 565-583. 
EC 2014, Canada's sixth national report on climate change, Government of Canada, viewed 1 March 2015, http://www.ec.gc.ca/cc/0BA54AAB-6E8E-4D48-B42C-DCBB09B27D10/6458_EC_ID1180-MainBook_high_min\%20FINALs.pdf

Emberley, S, Huttcheon, I, Shevalier, M, Durocher, K, Mayer, B, Gunter, WD \& Perkin, E 2005, 'Monitoring of fluid-rock interaction and $\mathrm{CO}_{2}$ storage througth produced fluid sampling at the Weyburn $\mathrm{CO}_{2}$-injection enhanced oil recovery site, Saskatchewan, Canada', Applied Geochemistry, vol. 20, pp. 11131-1157.

Global CCS Institute 2013, Aquistore: $\mathrm{CO}_{2}$ storage at the world's first integrated ccs project: project summary report, prepared by Petroleum Technology Research Centre, PTRC, Regina, Canada.

Greggs, DH 2000, 'The stratigraphy, sedimentology, and structure of the lower paleozoic deadwood formation of Western Canada' $\mathrm{PhD}$ thesis, University of Calgary.

Gunter, WD, Perkins, EH \& Hutcheon, I 2000, 'Aquifer disposal of acid gases: Modeling of water-rock reactions for trapping acid wastes', Applied Geochemistry, vol. 15, pp. 1085-1095.

Peck, WD, Bailey, TP, Liu, G, Klenner, RCL, Gorecki, CD, Ayash, SC, Steadman, EN \& Harju, JA 2014, 'Model development of the Aquistore $\mathrm{CO}_{2}$ storage project', Energy Procedia, vol. 63, pp. 3723-3734.

Rostron, B, White, D, Hawkes, C \& Chalaturnyk, R 2014, 'Characterization of the Aquistore CO2 project storage site, Saskatchewan, Canada', Energy Procedia, vol. 63, pp. 2977-2984.

US EIA 2014, Monthly Energy Review: February 2014, U.S. Energy Information Administration, Washington, viewed 1 March 2015, http://205.254.135.7/totalenergy/data/monthly/\#electricity.

Worth, K, White, D, Chalaturnyk, R, Sorensen, J, Hawkes, C, Rostron, B, Johnson, J \& Young, A 2014, 'Aquistore project measurement, monitoring and verification: from concept to CO2 injection', Energy Procedia, vol. 63, pp. 3202-3208.

Zambrano-Narvaez, GZ, Chalaturnyk, RJ \& Lang, P 2013, US Patent 8555712: Outside casing conveyed low flow impedance sensor gauge system and method. 